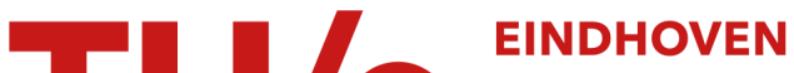 UNIVERSITY OF TECHNOLOGY
}

\section{Doppler ultrasound technology for fetal heart rate monitoring}

\author{
Citation for published version (APA): \\ Hamelmann, P., Vullings, R., Kolen, A. F., Bergmans, J. W. M., van Laar, J. O. E. H., Tortoli, P., \& Mischi, M. \\ (2020). Doppler ultrasound technology for fetal heart rate monitoring: a review. IEEE Transactions on \\ Ultrasonics, Ferroelectrics, and Frequency Control, 67(2), 226-238. [8848855]. \\ https://doi.org/10.1109/TUFFC.2019.2943626
}

\section{Document license: \\ TAVERNE}

DOI:

10.1109/TUFFC.2019.2943626

Document status and date:

Published: 01/02/2020

\section{Document Version:}

Publisher's PDF, also known as Version of Record (includes final page, issue and volume numbers)

\section{Please check the document version of this publication:}

- A submitted manuscript is the version of the article upon submission and before peer-review. There can be important differences between the submitted version and the official published version of record. People interested in the research are advised to contact the author for the final version of the publication, or visit the $\mathrm{DOI}$ to the publisher's website.

- The final author version and the galley proof are versions of the publication after peer review.

- The final published version features the final layout of the paper including the volume, issue and page numbers.

Link to publication

\section{General rights}

Copyright and moral rights for the publications made accessible in the public portal are retained by the authors and/or other copyright owners and it is a condition of accessing publications that users recognise and abide by the legal requirements associated with these rights.

- Users may download and print one copy of any publication from the public portal for the purpose of private study or research.

- You may not further distribute the material or use it for any profit-making activity or commercial gain

- You may freely distribute the URL identifying the publication in the public portal.

If the publication is distributed under the terms of Article 25fa of the Dutch Copyright Act, indicated by the "Taverne" license above, please follow below link for the End User Agreement:

www.tue.nl/taverne

Take down policy

If you believe that this document breaches copyright please contact us at:

openaccess@tue.nl

providing details and we will investigate your claim. 


\title{
Doppler Ultrasound Technology for Fetal Heart Rate Monitoring: A Review
}

\author{
Paul Hamelmann ${ }^{\circledR}$, Rik Vullings, Alexander F. Kolen, Jan W. M. Bergmans ${ }^{\circledR}$, Judith O. E. H. van Laar ${ }^{(}$, \\ Piero Tortoli ${ }^{\circledR}$, Senior Member, IEEE, and Massimo Mischi ${ }^{\circledR}$, Senior Member, IEEE
}

\begin{abstract}
Fetal well-being is commonly assessed by monitoring the fetal heart rate (fHR). In clinical practice, the de facto standard technology for fHR monitoring is based on the Doppler ultrasound (US). Continuous monitoring of the fHR before and during labor is performed using a US transducer fixed on the maternal abdomen. The continuous fHR monitoring, together with simultaneous monitoring of the uterine activity, is referred to as cardiotocography (CTG). In contrast, for intermittent measurements of the fHR, a handheld Doppler US transducer is typically used. In this article, the technology of Doppler US for continuous fHR monitoring and intermittent fHR measurements is described, with emphasis on fHR monitoring for CTG. Special attention is dedicated to the measurement environment, which includes the clinical setting in which fHR monitoring is commonly performed. In addition, to understand the signal content of acquired Doppler US signals, the anatomy and physiology of the fetal heart and the surrounding maternal abdomen are described. The challenges encountered in these measurements have led to different technological strategies, which are presented and critically discussed, with a focus on the US transducer geometry, Doppler signal processing, and fHR extraction methods.
\end{abstract}

Index Terms-Cardiotocography (CTG), Doppler ultrasound (US), fetal heart rate (fHR), fetal monitoring.

\section{INTRODUCTION}

C ARDIOTOCOGRAPHY (CTG) is the simultaneous and continuous recording of fetal heart rate (fHR) and uterine contractions (UCs). The CTG method was independently described in the late 1950s and early 1960s by Hon and Hess [1] in the United States, Alvarez and Caldeyro-Barcia [2] in Uruguay, and Hammacher [3] in Germany. Eventually, the first commercial fetal monitor was released by Hewlett Packard (Böblingen, Germany) in 1968 [4]. Since then, CTG has become the standard method to assess the fetal well-being before and during labor [5].

Manuscript received July 17, 2019; accepted September 19, 2019. Date of publication September 25, 2019; date of current version January 24, 2020. (Corresponding author: Paul Hamelmann.)

P. Hamelmann, R. Vullings, J. W. M. Bergmans, and M. Mischi are with the Department of Electrical Engineering, Eindhoven University of Technology, 5612 AP Eindhoven, The Netherlands (e-mail: p.c.hamelmann@tue.nl; r.vullings@tue.nl; j.w.m.bergmans@ tue.nl; m.mischi@tue.nl).

A. F. Kolen is with Philips Research, 5656 AE Eindhoven, The Netherlands (e-mail: alex.kolen@philips.com).

J. O. E. H. van Laar is with the Gynecology Department, Máxima Medical Center, 5504 DB Veldhoven, The Netherlands (e-mail: judith.van.laar@mmc.nl).

P. Tortoli is with the Department of Information Engineering, University of Florence, 50139 Florence, Italy (e-mail: piero.tortoli@unifi.it).

Digital Object Identifier 10.1109/TUFFC.2019.2943626
The primary objective of CTG is to reduce fetal mortality and morbidity by identifying fetuses at risk and determining the optimal timing of delivery [6]-[8]. It was shown that the use of CTG is associated with a decrease in the neonatal mortality [9]. However, it is well known that while CTG has high sensitivity, its specificity is limited, which has led to an increase in unnecessary Caesarian sections [10], [11]. The interpretation of CTG recordings is often challenging, and inter- and intra-observer variability are high [12]. Therefore, computer-assisted analysis of CTG recordings has been introduced [13]-[15] and, more recently, the extraction of features from the fHR and its variability have been investigated because of their potential to describe more directly the autonomous regulation of the fetus [16]-[18].

In general, the fHR can be measured by various technologies, which can be categorized into technologies for intermittent and continuous fHR measurements. They have different clinical objectives: while intermittent measurement techniques are used for the verification of fetal life or assessment of cardiac performance, continuous measurement techniques are used to obtain an fHR recording of a cardiotocogram.

During pregnancy, the fetal heart spontaneously starts beating at a gestational age (GA) of five weeks. This can be measured by a trained sonographer using diagnostic ultrasound (US) imaging systems, either with a transvaginal or, at higher GA, using abdominal US transducers [19]. Alternatively, the fHR can be obtained using handheld Doppler US devices (Doppler auscultation) [20]. At a later stage in pregnancy, experienced clinicians may also measure the fHR by listening to the sounds produced by the beating heart, using a fetal stethoscope or, in low-income countries, the so-called Pinard horn, which is a low-cost trumpet-shaped device [21].

Intermittent measurements are dependent on the operator and can only be used for spot-check assessment of the fetal conditions. However, especially during labor, techniques for continuous fHR recordings are required. The most accurate and reliable technique for continuous fHR monitoring is based on a direct fetal scalp electrode [22], which, however, can only be used when the membranes are ruptured. Due to its invasiveness and risk of infections, it is considered a nonpreferred method [23]. More recently, abdominal ECG measurements have allowed obtaining continuous fHR recordings noninvasively [24], [25]. Abdominal ECG requires advanced signal processing to deal with low signal-to-noise ratio (SNR) and the overlaying electric signal of the maternal ECG [25]. Especially during GA $=28-32$ weeks, when the fetus has formed a fatty 


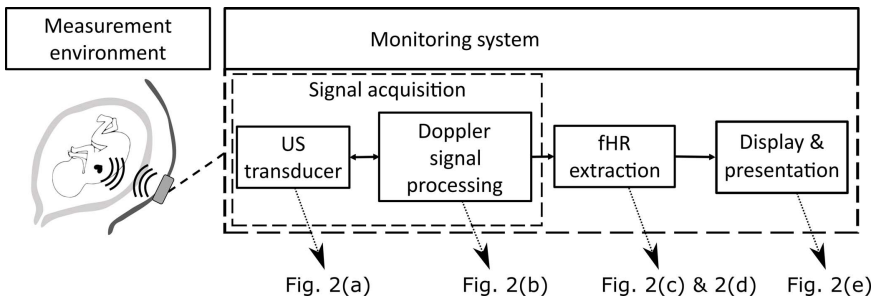

Fig. 1. Technical building blocks of a Doppler-based fHR monitoring system. In this review, a detailed section is dedicated for each of these blocks, and exemplary signals of the intermediate processing steps are shown in Fig. 2.

layer (vernix caseosa), acting as an electrical insulator, low SNR is a limiting factor [26]. Other methods, including fetal phonocardiography (fPCG) [27], fetal photoplethysmography (fPPG) [28], and fetal magnetocardiography (fMCG) [29], have been described in the literature but are not routinely used in the clinical practice.

At this time, the most common technology to measure the fHR of a CTG recording is based on the Doppler US, where the US transducer is fixed on the maternal abdomen for continuous recording. Yet, there are known technical limitations, such as the inaccurate beat-to-beat estimation of the fHR [30] and frequent periods of signal loss. Signal loss is especially severe for premature deliveries, high body-mass-index (BMI) mothers, multiple gestations, and during the second stage of labor [31]-[33], making the analysis of fHR recordings challenging. The Federation of Gynecology and Obstetrics (FIGO) recommends to only use fHR recordings for clinical analysis when, in no more than $20 \%$ of the recording time, an fHR signal is lost [34].

While some reviews describe the state-of-the-art in CTG or Doppler signal analysis, with a focus on feature extraction and clinical interpretation [35], [36], limited information is available for understanding the role of US Doppler signal acquisition, along with the associated limitations, challenges, and opportunities. The focus of this article lies on the technical building blocks of a Doppler US-based fHR monitoring system and their relation to possible error sources, which may prevent a successful fHR recording. Fig. 1 schematically shows these technical building blocks, and for each technical building block, exemplary signals are shown in Fig. 2. This article is structured as follows. In Section II, the measurement environment is thoroughly characterized, including the clinical setting, the anatomical structures within the maternal abdomen, and the mechanical physiology of the fetal human heart. In Section III, the monitoring system is described. According to the schematic shown in Fig. 1, the main features of the US transducer (Section III-A), Doppler signal processing (Section III-B), fHR extraction (Section III-C), and display/presentation (Section III-D) are reported. A discussion on the current technology and design choices (Section IV) is followed by our views on future perspectives (Section V).

\section{Measurement EnVironment}

\section{A. Clinical Setting}

CTG is performed in both the antenatal and intrapartum periods. Commonly, for GA $\geq 28$ weeks, a cardiotocogram is (a)

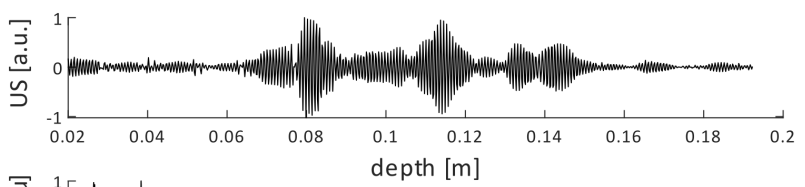

(b)

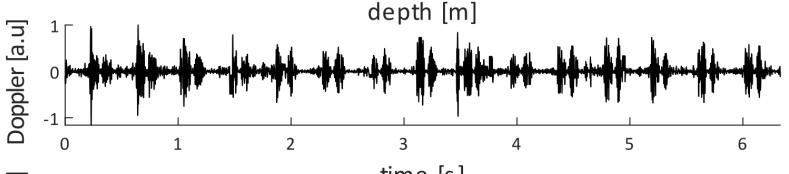

(c) 5 time $[s]$

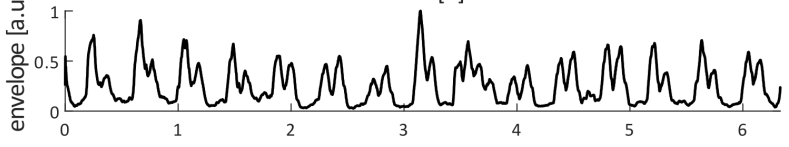

(d)

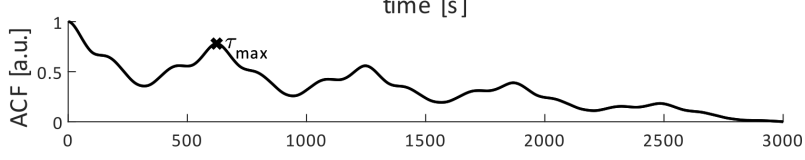

(e)

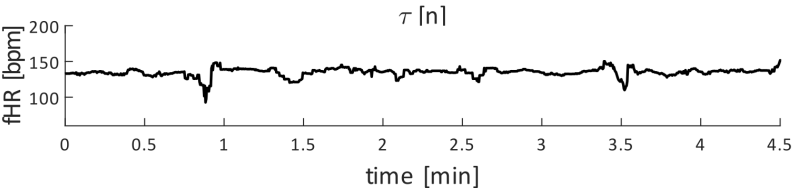

Fig. 2. Exemplary signals after intermediate signal processing steps. (a) Raw radiofrequency US signal. (b) Nondirectional Doppler signal. (c) Envelope of the Doppler signal. (d) ACF. (e) fHR signal trace. Note different units on the abscissas.

routinely performed for a minimum recording time of $30 \mathrm{~min}$ to identify fetuses at risk [37]. The monitoring frequency strongly depends on the individual clinical risk assessment and can vary from single recordings on an outpatient to several recordings per day [36], [37]. When a mother is admitted to the labor ward, a 30-min test is frequently performed for initial fetal well-being assessment. Continuous CTG monitoring is routinely initiated during the first stage of labor and then continued until the delivery [37].

For the acquisition of the fHR signal in the clinical practice, a skilled personnel palpates the fetal presentation and moves the US transducer across the maternal abdomen while listening to the Doppler signal, made audible by the fHR monitoring system [38]. For better acoustic coupling, US gel is applied between maternal skin and the US transducer [38]. When the heart lies within the measurement volume of the transducer, the clinician fixates the position of the transducer using a flexible belt and commences continuous fHR recording [10].

During labor, mothers are encouraged to frequently change their position from reclining to sitting and to walking position [39]; immersion into water during labor is also possible [40]. Medical equipment is required to work for all the mother's positions [41] and needs to function in the hectic labor environment, where the clinical staff repetitively interacts and takes care of mother and fetus using various clinical procedures.

\section{B. Maternal Abdomen}

Various anatomical structures and tissue types are present between the fetal heart and the US transducer. Transmitted US waves propagate through the maternal skin and subcutaneous tissue, the uterine muscle, the amniotic sac filled with amniotic fluid, and the chest of the fetus. When they 


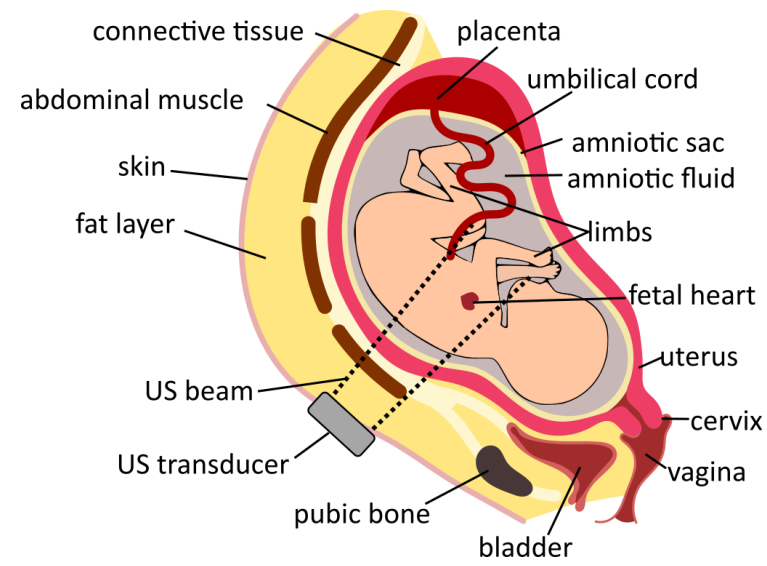

Fig. 3. Schematic of the anatomical structures within the maternal abdomen. For the depicted cephalic presentation, the US transducer is positioned at a typical location.

finally reach the fetal heart, they are reflected toward the US transducer following the same acoustic path in the reverse order [42]. An illustration of the anatomical structures within the maternal abdomen is shown in Fig. 3.

The distance between the US transducer and fetal heart depends mainly on the thickness of the subcutaneous fatty tissue, which can strongly vary between mothers of different countries [43] and different socio-economic status [44]. In addition, the fetal presentation affects this distance and determines under which angle the heart is insonified. For mothers with an average BMI, the fetal heart to transducer distance is typically $4-18 \mathrm{~cm}$. While the fetus can freely move within the uterus at early GA, the most prevalent fetal presentation at term is the cephalic presentation ("head down") [45], and the frequency of gross body movement is reduced [46]. Velazquez and Rayburn [47] characterized fetal movement (FM) based on their duration and strength. Gross body movement was described as a strong rolling and stretching motion of the body sustained over a period of 3-30 s. Shorter simple movements of fetal extremities vary in strength and may be an isolated event and last up to $15 \mathrm{~s}$. In addition, a weak motion of the fetal chest is present as a result of the fetal breathing and fetal hiccups [47].

Throughout gestation, the uterus grows from a fist-sized organ toward an organ that occupies most of the abdominal cavity, reaching from the pelvic bone to the xiphoid process [42]. Blood supply to the uterus is provided by the uterine arteries [42]. In the antepartum period, the uterus starts contracting weakly, irregularly, and nonfrequently to prepare for the expulsion of the fetus [48]. In the intrapartum period, UCs become stronger, more frequent, and last longer, with a duration of 10-30 s every 15-30 $\mathrm{min}$ at the onset of labor and up to 60-s long UCs every 2-3 min during the expulsion phase [42].

The placenta can attach to any side of the uterus, but anterior, posterior, and lateral placental locations are most common [49]. At term, maternal blood flow through the placenta is approximately $600-700 \mathrm{~mL} / \mathrm{min}$. The free-floating umbilical cord, which typically consists of two umbilical arteries and one umbilical vein, provides nutrition and oxygen

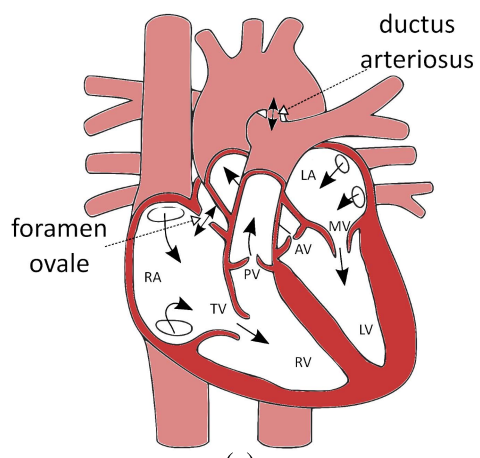

(a)

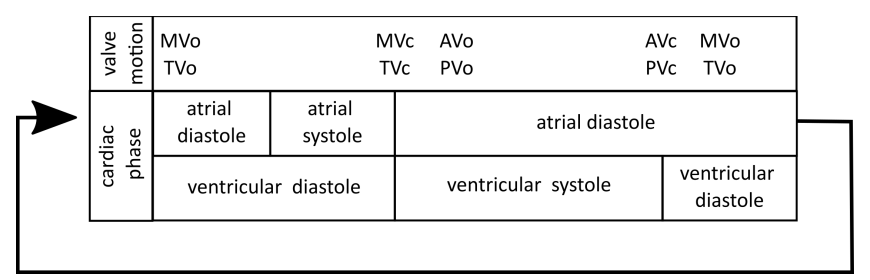

(b)

Fig. 4. (a) Anatomy of the fetal heart, with left atrium (LA), right atrium (RA), LV, RV, TV, pulmonary valve (PV), AV, and MV. The foramen ovale shunts the RA and LA, and the ductus arteriosus shunts the aorta with the pulmonary artery allowing oxygenated blood to bypass the pulmonary circulation. The black arrows indicate the direction of blood flow. (b) Cardiac phases and valve motion during a cardiac cycle. The indexes $\mathrm{o}$ and $\mathrm{c}$ indicate the opening and closing of the valves, respectively.

from the placenta to the fetus and transports waste products such as carbon dioxide to the mother [49].

The fetal heart lies within the chest of the fetus and is surrounded by the ribs. Ossification of the fetal skeleton develops throughout gestation and is at term far from complete [50], [51]. In addition, the fetal lungs are filled with fluid, which favors the propagation of US waves, by avoiding they are blocked by air [52].

\section{Anatomy and Physiology of the Fetal Heart}

During gestation, the heart is among the first organs which are formed and it develops from a tube-like organ, at day 21 of gestation, to a four-chambered heart [42].

Luewan et al. [53] used spatiotemporal image correlation M-mode imaging to derive the normal fetal cardiac dimensions for GA $=14-40$ weeks. They found that the fetalheart biventricular outer diameter (BVOD) can be described by $\mathrm{BVOD}=-2.3624+(0.2769 \mathrm{GA})-\left(0.0030 \mathrm{GA}^{2}\right)[53]$, leading to a term BVOD of $3.9 \mathrm{~cm}$.

The anatomy and physiology of the fetal heart differ from the anatomy and physiology of the adult heart. Since blood is oxygenated in the placenta, there is no need to pump the entire blood through the lungs. Therefore, two shunts are present in the fetal heart [see Fig. 4(a)]. The ductus arteriosus connects the pulmonary artery with the aorta, and the foramen ovale connects the left and right atriums. In that way, most of the oxygenated blood coming from the placenta directly flows into the systemic circulation [42].

Despite the presence of these two shunts, the same electromechanical cardiac events of an adult fetal heart are present in the fetal heart. The cardiac cycle can be divided into 
a diastolic and systolic phase for both atria and ventricles, respectively [see Fig. 4(b)]. In early diastole, the mitral valve (MV) and tricuspid valve (TV) are open and blood flows passively into the ventricles. In late diastole, both atria contract to complete the filling of the ventricles. At the beginning of the ventricular systole, all cardiac valves are closed and the blood volume in the ventricles does not change. Due to the contraction of the ventricles (isovolumetric contraction), the blood pressure in the ventricles increases, which opens the pulmonary valve and aortic valve (AV), allowing blood to be ejected [42].

The complex 3-D motion and deformation of myocardial tissue during contraction are determined by the orientation of myocardial fibers. Tutschek et al. [54] used the tissue Doppler imaging to measure the tissue velocities at different sites of the fetal heart at various GAs and characterized the systolic tissue velocity of right ventricle (RV) and left ventricle (LV) with $v_{\mathrm{RV}}=0.017 \mathrm{GA}^{2}-0.5944 \mathrm{GA}+9.0522 \mathrm{~cm} / \mathrm{s}$ and $v_{\mathrm{LV}}=0.009 \mathrm{GA}^{2}-0.2104 \mathrm{GA}+5.0742 \mathrm{~cm} / \mathrm{s}$, respectively. Similar values have been found by Elmstedt et al. [55]. Reed et al. [56] investigated the blood flow through the fetal cardiac vales using the pulsed-wave (PW) Doppler with a linear array scanner, and maximal flow velocities of up to $v=70 \mathrm{~cm} / \mathrm{s}$ have been measured in the aorta.

After the first spontaneous beating of the fetal heart at $\mathrm{GA}=5$ weeks, the fHR rapidly increases to an average value of $\mathrm{fHR}=170$ beats per minute $(\mathrm{bpm})$ at $\mathrm{GA}=10$ weeks [19] and then slowly decreases until term [57]. Pildner von Steinburg et al. [57] analyzed 78852 CTG traces and concluded that the normal fHR, which is nonindicative for any fetal compromise, lies in the range of fHR $=110-160 \mathrm{bpm}$. In the developing fetal heart, the electrophysiological channels in the myocardial tissue are immature, and calcium ions are removed more slowly from the myocardial tissue after contraction compared to the adult fetal heart [59]. Consequently, to deal with the increased cardiac demand, rather than contracting more strongly, the fetal heart typically responds by rapidly increasing its heart rate [59].

\section{MONITORING SYSTEM}

\section{A. Ultrasound Transducer}

1) Physics of Ultrasound Propagation: When a US transducer is positioned on the maternal abdomen, the transmitted US waves propagate through the maternal abdomen and interact with the tissue structures described in Section II. The transmission and specular reflection of US waves at the boundary between two media with different acoustic properties can be characterized by their difference in acoustic impedance $Z=\rho c$, with medium density $\rho$ and US propagation velocity $c$. A detailed explanation can be found in [60]. Next to specular reflections, US scattering into all directions occurs when US waves interact with structures, like the red blood cells, which are smaller than their wavelength, $\lambda=c / f_{0}$ with transmission frequency $f_{0}$. Scattered US waves are typically lower in amplitude compared to specular reflections. Both specular reflection and scattering contribute to the echo US wave, which is eventually received by the transducer on the abdominal surface. An example of such received US signal is shown in Fig. 2(a).

The intensity $I$ of a propagating US wave decreases as a function of depth $z$ when propagating through the abdomen as follows:

$$
I(z)=I(0) e^{-\alpha f_{0} z}
$$

with the attenuation coefficient, $\alpha$, representing the energy loss due to both absorption and scattering. The attenuation coefficient is typically approximated as a linear function of the US frequency $f_{0}$, expressed in $\mathrm{dB} / \mathrm{cm} / \mathrm{MHz}$, although the actual relationship is mostly nonlinear [60]. Therefore, as the fetus may lie deep within the uterus, US transducers for fHR as well as FM measurements typically operate in a lowfrequency range: $f_{0}=1-3 \mathrm{MHz}$ [32], [35], [61]-[70]. This is especially important for measurements on mothers with a large BMI, because the fat layer increases the US transducer to fetal heart distance and is characterized by high US attenuation [71]. A comprehensive overview of the acoustic properties of the anatomical structures in the maternal abdomen can be found in [72].

2) Transducer Geometry: For fHR monitoring, it is required that the fetal heart lies within the field of view (FOV) of the employed transducer aperture. Typically, for intermittent measurements using a handheld Doppler probe, the US transducer uses a single, circular, piezoelectric element for transmission [35].

For such a single-element aperture, the beam profile has a full-width-at-half-maximum (FWHM) in the Fraunhofer zone (far field) that, at a depth $z$, can be approximated by

$$
\mathrm{FWHM}=1.4 z \lambda / 2 a
$$

where $a$ is the transducer element radius [60]. Given the typical fetal heart to transducer distance (see Section II-B), the fHR monitoring system indeed operates in the Fraunhofer zone, which starts at a depth $z_{F}=a^{2} / \lambda$. Equation (2) establishes an inverse relationship between the width of the beam profile and both diameter, $2 a$, and US frequency, $f_{0}=c / \lambda$. Increasing the transmit frequency $f_{0}$ reduces the FWHM, and, thus, the FOV of the transducer, such that the fetal heart more likely moves out of view. In addition, increasing $f_{0}$ comes at the cost of reduced penetration depth. On the other hand, decreasing $f_{0}$ reduces the sensitivity to measure flow and tissue velocities.

Jensen and Svendsen [73] used the Field II US simulation program to characterize the transducer design requirements for a handheld, portable, and easy-to-use fHR monitoring [74]. They concluded that a diverging beam, generated by a single convex transducer with a width of $10 \mathrm{~mm}$, curvature radius of $100 \mathrm{~mm}$, and $f_{0}=2 \mathrm{MHz}$, leads to the best balance between signal strength and robustness to fetal and maternal movement [74].

For continuous monitoring of fHR, the transducer's FOV can be increased using an array with multiple elements. Typically, in such an array, a central transducer element is surrounded by multiple elements in a circular pattern [61], [75]. Such transducer geometry is shown in Fig. 5(a), for which the corresponding generated US pressure field was generated 


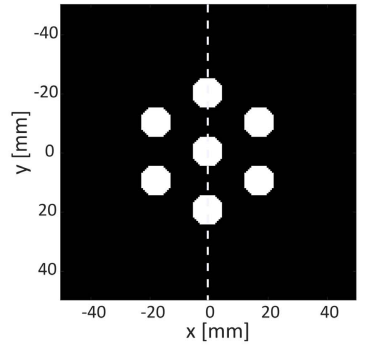

(a)

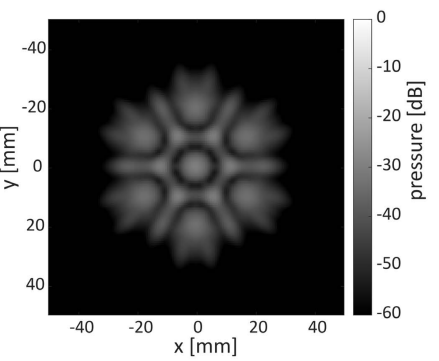

(b)

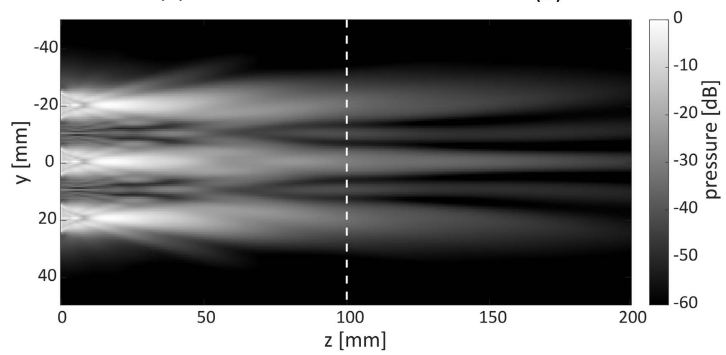

(c)

Fig. 5. (a) Geometry of a multi-element transducer used for continuous fHR monitoring. The corresponding pressure field was generated using the $k$-wave simulation program using a transmission frequency of $f_{0}=1 \mathrm{MHz}$. (b) US pressure field in the $x y$-plane at a depth $z=100 \mathrm{~mm}$. (c) US pressure field in the $z y$-plane at $x=0 \mathrm{~mm}$.

using the $k$-wave [76] simulation program [Fig. 5(b) and (c)]. The US waves transmitted by such US transducers interfere, leading to local variations in the US pressure within the medium [77]. The local pressure variations affect the amplitude of the reflected US echo, which is eventually received by the array. Since the fetal heart is large compared to the spatial dimensions of these local variations, i.e., there is always a part of the fetal heart sufficiently insonified [53], these local variations do not hamper the fHR monitoring. However, these variations do have an effect on the received signal strength in preterm fetuses. Furthermore, these local variations affect the performance of methods addressed to estimate the fetal heart location (fHL) [61], [62]. Usage of a multiple-array transducer has been described to allow insonification of different sites of the uterus, with the aim of measuring FM along with the estimation of the fHR [64], [75]. Furthermore, flexible transducer arrays which have the potential of measuring the fHR for all fHLs have also been described [78]-[80].

3) Transducer Positioning: The FOV depends on the US transducer geometry and frequency and sets the volume in which the fHR can be measured. As a result of fetal descent in the birth canal, FM, the abdominal shape-altering effect of UC, and the maternal pushing during the second stage of labor, the fetal heart may move out of the transducer's FOV [81]. Furthermore, the location of the fetal heart also changes due to the filling of the bladder [71]. A filled bladder occupies more space in the pelvic cavity and possibly pushes the uterus upward [71]. Therefore, correct transducer positioning is crucial for continuous monitoring of the fHR.

Before positioning of the US transducer, the fetal presentation is palpated by a clinician. Palpation of the fetal presentation can be difficult in preterm pregnancies as well as for mothers with a high BMI [82]. Sometimes, US imaging is required to further assist in finding the fHL [83]. Clinicians swipe the US transducer across the maternal abdomen while listening to the Doppler signal and subsequently fix the US transducer using a flexible belt. This may be a tedious task and requires experienced clinicians. To support clinicians in positioning the US transducer, methods have been developed to estimate the fetal location [61], [62], [77]. These methods exploit a multi-element array and measure the Doppler power in each individual transducer element, which is then put into a probabilistic framework for fHL estimation. In that way, a visual feedback can be provided to the clinician to position the US directly above the fetal heart. This improves signal quality, reduces the probability that the fetal heart moves out of the FOV during continuous monitoring, and improves the clinical workflow when the fHR signal is lost [61], [62]. For fHR monitoring independent of the transducer positioning, the FOV may be increased to cover all potential fHLs by integrating multiple elements into a single flexible transducer array [78], [80]. In a patent described by Groberman et al. [84], a US array may be arranged to yield different modes of operation, one using a low $f_{0}$ for fetal heart localization and the other one using a high $f_{0}$ for fHR measurement.

For monitoring twins or triplets, multiple US transducers are positioned on the maternal abdomen. Careful positioning is required to guarantee that both fHRs are correctly registered and no duplicate monitoring of the same fetus occurs [7]. It is recommended to use a multi-channel monitor that allows simultaneous recording of both fetuses. An alarm is launched when the fHRs are too similar to prevent the risk that the fHR of the same fetus is measured twice [7]. Correct and unambiguous detection of twin-fHR is crucial, as there is a trend of increasing twinning rates in the developed countries [85] and twin pregnancies have increased mortality and morbidity [86].

Another consequence of incorrect US transducer positioning is the chance of recording the maternal heart rate (mHR) instead of the fHR [81], [87]. Esplin and Eller [87] reported cases where the mHR was misinterpreted as fHR. This commonly occurred after repositioning of the patient, after FM, or during pushing in the second stage of labor, when the baseline of mHR increases and falls in the typical range of fHR [87]. Therefore, simultaneous recording of $\mathrm{mHR}$ is recommended [87].

4) Ultrasound Safety in Obstetrics and Gynecology: When US interacts with tissue at sufficiently high intensities, it potentially causes biophysical harm due to heating, mechanical effects, cavitation, or chemical effects [88]. These effects require special attention as the fetus is particularly sensitive during early pregnancy [89]. However, until now, there is no clinical evidence that US used in obstetrics, and gynecology has any harmful effect on the fetus when following the international recommendations of expert groups [89]. In the USA, the acoustic output of medical devices is directly regulated by the Food and Drug Administration (FDA). US transducers used for fetal imaging need to comply with the FDA guidelines (Track-1) of a maximum spatial-peak-temporal-average intensity $I_{\text {spta }}=94 \mathrm{~mW} / \mathrm{cm}^{2}$ and a maximum spatial-peakpulse-average $I_{\text {sppa }}=190 \mathrm{~W} / \mathrm{cm}^{2}$ [90]. US systems for fHR monitoring produce acoustic output power levels that 

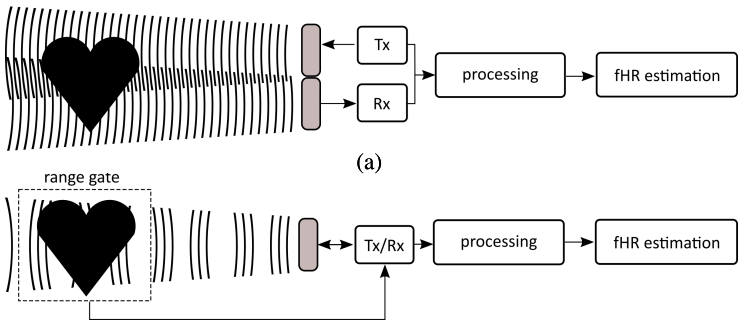

(b)

Fig. 6. (a) CW Doppler acquisition. (b) PW Doppler acquisition.

are significantly lower. Therefore, there is no contraindication for use even for extended monitoring periods [89]. Nevertheless, in general, obstetric US should not be carried out for nonmedical reasons, and US exposure should be as-low-asreasonably achievable [89], [91].

\section{B. Doppler Signal Processing}

1) Doppler Modes: When a US wave is reflected by a moving target (see Section II-A1), its frequency changes accordingly. This shift in frequency is known as the Doppler frequency shift, $f_{d}$, which is described as follows:

$$
f_{d}=\frac{2 f_{0} v \cos (\theta)}{c}
$$

where $v \cos (\theta)$ is the velocity of the target along the direction of the US beam. In general, if the target approaches the transducer, the received frequency increases (i.e., $f_{d}>0$ ), while it decreases when the target moves away.

Two different modes of Doppler US exist, continuous wave (CW) Doppler and PW Doppler, and both are applied for fHR monitoring. In general, handheld systems used for intermittent measurements typically employ CW US, while fHR monitoring during a CTG recording is typically obtained using the PW Doppler systems.

In the CW Doppler systems [see Fig. 6(a)], at least two transducer elements are required, one acting as the transmitter and the other one acting as the receiver. The sample volume (SV) is defined as the region where the US beams of transmitter and receiver overlap. In a PW Doppler system [see Fig. 6(b)], the transducer transmits US pulses with a certain pulse duration $(T)$ and pulse repetition frequency (PRF). The reflected US pulses are sampled at a time corresponding to a specific depth from the transducer, a process called range gating. The range gate duration, together with $T$, defines the length of the SV. The width of the SV is defined by the geometry of the transmitted US beam [60]. For fHR monitoring systems, typically long SVs are used, making the fHR recordings more robust against the movement of the fetal heart and helping with positioning of the US transducer. This comes at the cost of spectral broadening and increased chance that multiple tissue structures move within the SV. To reduce the signal ambiguity caused by pulsating maternal arteries, Wohlschlager and Franck [92] described in a patent the automatic adjustment of the range gate duration based on the assessment of periodicity of the acquired Doppler signals. Furthermore, multi-depth Doppler acquisitions have been proposed, in which the US signal is range-gated at various depths for improved fHR estimation and FM classification [63], [75].
In another patent, Doppler signals are acquired using multiple range gates, and it is tested whether measured fHRs fall in the range of a typical fetal heart [93].

In PW Doppler systems, each transmitted US pulse produces one sample of the Doppler signal. It should be noted that for the PW Doppler, the phase shift, rather than the Doppler frequency shift, $f_{d}$, between pulses is actually measured. Nevertheless, (3) can still be used to measure the target velocity [94].

Since the PRF represents the sampling frequency of the Doppler signal, it sets a limit to the maximum measurable velocity $v_{\max }= \pm c_{0} \mathrm{PRF} /\left(4 f_{0} \cos (\theta)\right)$ without aliasing. As described in Section II-C, the tissue velocities of the $\mathrm{LV}$ and RV are sufficiently low (i.e., $v_{\mathrm{RV}}=12.5 \mathrm{~cm} / \mathrm{s}$ and $v_{\mathrm{LV}}=11.1 \mathrm{~cm} / \mathrm{s}$ ) to allow measuring a Doppler signal without aliasing for US frequencies in the typical range of $f_{0}=1-3 \mathrm{MHz}$. However, aliasing may occur for faster blood velocities measured at high US frequencies when the fetal heart is located deep within the body.

2) Doppler Signal Extraction: The received US radiofrequency echo signals are modulated both in amplitude, depending on the US wave propagation through tissue and the scanning condition, and in phase, depending on the depth of the target [75]. A large variety of demodulation techniques exist, and the reader is referred to [95] and [96] for a comprehensive description. The most widely used demodulation for CW and PW Doppler is the phase-quadrature demodulation, which consists in mixing the received US signal with the carrier signals $\cos \left(2 \pi f_{0} t\right)$ and $\sin \left(2 \pi f_{0} t\right)$, to yield, after low-pass filtering, the base-band in-phase $(I)$ and quadrature $(Q)$ components, respectively. After the range gate process described in Section III-B1, a bandpass filter is applied to remove clutter produced by the slow-moving tissue, FMs, and UC [70], [75], as well as possible maternal blood vessel interferences as well as fast isolated FMs [14], [54].

It should be noted that in the fHR monitoring often only a single-signal channel ( $I$ or $Q$ ) is used, which is referred to as a nondirectional Doppler US. The demodulation for a nondirectional signal can be implemented using a few passive components and, hence, has the advantage of reduced costs. An example of such nondirectional Doppler US signal is shown in Fig. 2(b). By analyzing the phase relation in the $I Q$ signal, the forward and reverse signal components can be extracted using a variety of methods [97], which are implemented using digital circuits [98]-[100]. This is referred to as directional Doppler US. Here, we highlight again the applications objective of measuring the fHR for the assessment of fetal well-being before and during labor. This is different from standard US Doppler modalities, which aim at in-depth analysis of cardiac flow dynamics. In those modalities, the Doppler signal is further processed and a velocity-time representation is typically provided for specific locations, defined by the SV. In the Doppler systems for fHR measurement, the SV is large compared to the fetal heart, and only a global assessment of cardiac rhythm is possible.

\section{Fetal Heart Rate Extraction}

1) Signal Content: Shakespeare [70] analyzed the signal content of the Doppler signals obtained with a commercially 
available fHR monitor and was able to identify six cardiac events: atrial contraction (Atc), ventricular contraction (Vtc), mitral valve opening (MVo), mitral valve closing (MVc), aortic valve opening (AVo), and aortic valve closing $(\mathrm{AVc})$. However, these events are hardly visible in the Doppler signal at the same cardiac cycle. In most Doppler recordings, only four cardiac events can be reliably detected [63], [68]. Depending on the transducer positioning and insonification angle, the acquired Doppler signals of the same fetal heart may significantly differ [69]. Rotation and movement of the fetus may completely change the Doppler signal content over time. The most dominant component of the Doppler signal is due to cardiac wall movement [54], [70], with Vtc having only $30 \%$ of the amplitude compared to Atc [70].

2) Fetal Heart Rate Estimation: For fHR estimation, first, the envelope of the Doppler signal is detected and subsequently fed into an fHR estimation algorithm. For envelope detection, the Hilbert transform is typically used to calculate the analytic signal. The amplitude is, thus, detected and subsequently low-pass filtered [64], [69], but other envelope detection methods may also be considered [27]. An example of such envelope signal is shown in Fig. 2(c). Commercially available fHR monitor typically use the envelope of the nondirectional Doppler signal, while other algorithms are based on the envelope of the directional Doppler signal [63], [77].

In early fHR monitors (first-generation fHR monitors), the fHR was estimated from the time between peaks in the envelope signal of two successive heartbeats. However, due to the noisy nature of the signal and multiple peaks within one cardiac cycle, reliability and accuracy of the estimated fHR were poor [101]. With the increasing availability of microprocessors, in modern systems (second-generation fHR monitors), these problems are overcome by the implementation of an autocorrelation function (ACF) for fHR estimation [101], [102]. In an ACF approach, the Doppler envelope signal is correlated with a delayed copy of itself to detect the periodicity within the signal. A standard implementation may be defined as follows:

$$
\operatorname{ACF}[\tau]=\sum_{j=0}^{N-\tau} x[n+j] x[n+j+\tau], \quad 0 \leq \tau \leq N
$$

where $x$ is the analyzed signal, $n$ is the first sample in the autocorrelation window, $N$ is the length of the ACF window expressed in samples, and $\tau$ is the delay [69]. The delay at which the ACF shows a maximum, $\tau_{\max }$, can be converted into an fHR estimate, expressed in bpm, by fHR $=f_{s} 60 / \tau_{\max }$, with $f_{s}$ being the signal sampling frequency. The ACF applied to an exemplary envelope signal is shown in Fig. 2(d). Most fHR monitors in the clinical practice provide the fHR estimate at evenly sampled data points using the sample-and-hold methods. The internationally established standard is to provide the fHR estimate every $0.25 \mathrm{~s}$, which guarantees that no heart beat is missed at a maximal fHR of $240 \mathrm{bpm}$ [103] but may result in duplicate and incorrect fHR samples. Therefore, algorithms have been developed to recover the time event series of consecutive heart beats from the evenly sampled fHR recordings [103], [104].
By comparing the Doppler signal waveform of one cardiac cycle with the waveforms of other cardiac cycles within the same window $N$, only an average fHR estimate is obtained. It is known that due to low SNR, the beat-to-beat accuracy of a Doppler-based fHR monitor is lower compared to electrophysiological measurements, which can make use of the distinct morphology of the ECG signal [105]. Improved robustness of fHR estimation using the ACF comes at the cost of reduced beat-to-beat accuracy [67]. Therefore, Wrobel et al. [105] proposed to retrospectively correct fHR variability features extracted from the fHR trace obtained with the ACF approach, using linear regression.

More recently, the ACF method has been further improved to obtain accurate beat-to-beat fHR estimation [30], [69]. Peters et al. [30] proposed a two-step approach, in which global estimates of peak location are obtained from a low-passfiltered envelope signal and subsequently used to define the time window, in which the ACF is calculated. In this way, they guaranteed that only two successive heart cycles contribute to the fHR estimate [30]. In [69], the window size and execution timing of the ACF are dynamically updated based on the latest estimate of the fHR. Furthermore, peaks found in the ACF are given a higher probability of corresponding to the correct cardiac cycle if they fall in the range of the previously determined fHR [69].

In [63], the fHR estimation from directional Doppler signals is compared with that from nondirectional Doppler signals. Improved performance is shown for the fHR estimation based on the directional Doppler signals.

It is important that the quality of the Doppler signals and the associated reliability of fHR estimation are assessed prior to the CTG analysis, and if required, recordings with low quality are removed [106]. A common strategy for signal quality assessment is based on assessing the prominence of the peak found in the ACF [69]. In addition, signal quality may be directly evaluated from features obtained in the raw Doppler signal, such as entropy or wavelet coefficients [107], or using template-matching approaches [108].

3) Signal Simulation for Algorithm Development: Signal processing and analysis are executed on proprietary systems, and on the latest systems, only the estimated fHR is available as digital output. For the research community, it is often challenging to access the raw Doppler US signals acquired with a commercially available US transducer, which prevents the advancement of accurate and robust fHR estimation algorithms. In addition, data acquisition on the vulnerable patient population, i.e., the developing fetus and the pregnant mother, is associated with high organizational burden.

In vitro and in silico models have been developed, which allow the generation of artificial signals suitable for algorithm development. Already in 1986, Morgenstern et al. [109] developed a test setup to compare the beat-to-beat accuracy of commercial fHR monitors. This setup consists of a diaphragm in a water tank which is brought into a predefined periodical motion, corresponding to typical fHR values. The motion of the diaphragm was tuned such that the frequency of acquired Doppler signals matches those of in vivo signals [109]. In 
a different study, a valve mimicking the diaphragm, brought into motion by a pulsatile pump, is placed in a semicircular water bath allowing insonification by the US transducer under calibrated angles [110]. The setup was used to prove that the insonification angle between the US transducer and the heart valve has a negligible effect on the estimation of fetal cardiac time intervals [110]. In [111], the linear motion of an electrical relays armature is controlled via a microcontroller to create Doppler shifts similar to those caused by the cardiac wall as well as by valve motion. However, this setup is only applicable for experiments in air.

For more realistic measurements, in [61] and [62], an experimental setup was designed, in which a chicken heart is brought into a beat-like motion pattern within a water tank. US attenuation due to fat was obtained by adding an acoustic absorbing layer between the target and the US transducer, and this setup allows mimicking the out-of-beam motion of the heart due to FM or transducer displacement [77]. A limitation of the described setups is that no real heart contraction can be mimicked, disregarding the complex sequence of events during a cardiac cycle [see Fig. 4(b)].

As an alternative to experimental data, artificial Doppler signals may be created using simulations. Lee et al. [112] recorded the in vivo audio signal via the output jack of a handheld Doppler device [112]. The heart beats within the signal were manually annotated to create a template, which can be used to generate Doppler signals corresponding to predefined fHR traces and, by the addition of noise, of different SNRs [112]. Similarly, Voicu et al. [63] analyzed the statistical characteristics of a real directional envelope signal. This was used to generate a directional envelope signal corresponding to either the forward or backward component of the Doppler signal, or, by combining both components, a nondirectional Doppler envelope signal.

\section{Display and Presentation}

To help positioning the US transducer on the maternal abdomen or to enable diagnostic analysis, the Doppler signal is often made audible by the monitoring system [38]. This is possible because the Doppler frequency shifts produced by the tissue velocities of a cardiac contraction fall in the low $\mathrm{kHz}$ range, i.e., $f_{d}<1 \mathrm{kHz}$, which is within the audible range of a human [70].

The acquired Doppler signals are typically not directly shown on the fHR monitor. Here, we highlight again the difference from clinically used spectral Doppler measurements, in which the acquired Doppler signals are presented in a velocity-time curve enabling the quantitative analysis of tissue and blood velocities. Instead, only the estimated fHR signal [compare Fig. 2(e)] is directly sent to the CTG monitoring system, where it is displayed together with the UC signal. In handheld systems for intermittent measurements, the fHR is often shown on an LCD screen on the device itself. In proprietary company products, the raw Doppler signals remain inaccessible, which makes the evaluation and development of Doppler signal processing and analysis techniques challenging [113].

\section{Discussion}

This article provides an overview of the state-of-the-art technology of Doppler-based fHR monitoring. Key aspects to be considered for designing a Doppler-based fHR monitoring system are highlighted and discussed. One of these aspects is the FOV of the transducer. A large FOV helps with positioning the US transducer and makes the recording more robust to fHL changes. However, a drawback of large FOVs is that adjacent moving tissue structures contribute to the Doppler signal, leading to clutter artifacts and reduced SNR by spectral broadening. The FOV can be influenced by the transducer geometry, i.e., the radius of the individual transducer elements, the number of elements, and their spacing within the array, as well as the used transmission frequency (i.e., a lower frequency increases the size of the beam).

Although lower frequencies are advantageous in terms of low signal attenuation, higher frequencies lead to improved sensitivity to measure flow and tissue velocities. The choice between these design options is strongly dependent on the intended use case, e.g., intermittent versus continuous monitoring, and the target population in which the fHR monitor is used.

The choice of the appropriate Doppler mode is mainly determined by the possible need for depth adjustment, which is only possible in PW systems. Although the PW system receiver architecture is slightly more complex compared to CW systems, obtaining the Doppler signal from a specific depth allows optimizing the SNR of the signal. Similarly, acquisition of a directional Doppler signal is not as simple as the acquisition of a nondirectional Doppler signal. However, with currently available processing devices such as field programmable gate arrays (FPGAs), there is no reason to give up the improved Doppler signal analysis offered by directional approaches.

The most commonly applied method to estimate the fHR from the acquired Doppler signals is based on the ACF approach, in which the periodicity within the signal is determined. The advantage of this technique, compared to, e.g., peak detection methods, is its robustness to extract the fHR from low SNR signals. Here, the key parameter to be tuned is the length of the ACF window, with an improved robustness at longer length, but reduced beat-to-beat accuracy. When no beat-to-beat accuracy is required, a long window length should be used.

After more than 50 years, CTG plays a central role in the clinical decision making, and it is likely to maintain this role in the future [5]. For Doppler-based fHR monitoring technology, the key limitation is obtaining the correct transducer position on the maternal abdomen and the associated problems of signal loss. New innovations should tackle this problem, leading to more robust monitoring of the fHR, improved fetal health assessment, and improved clinical workflow.

Another limiting factor for improving the fHR estimation is the restricted access to raw US data, which is internally processed on proprietary fHR monitors of different companies. The situation is similar to that of clinical US imaging scanners, which do not provide such access to researchers. In this 
case, the problem has been overcome through the introduction of open scanners that have significantly boosted US imaging research [114]. Providing access to raw US data might help the scientific community to develop improved signal processing methods for more accurate and robust estimation of the fHR.

\section{Future Perspectives}

\section{A. Improving Fetal Health Assessment}

Future technological developments of the Doppler-based fHR monitoring will be driven by the need for improved fetal health assessment based on information not easily available by other technologies such as fECG, fMCG, fPCG, or fPPG. Although FM identification is already a part of most fetal monitors, improved signal analysis may add further clinical value of FM monitoring in CTG [115]. It was shown that appropriate processing of Doppler signals obtained during CTG recording enables an objective assessment of fetal activity [116].

Besides fHR estimation alone, studies have investigated the possibility of extracting the timing of cardiac events from Doppler US signals for improved diagnostic capabilities [117]-[119]. This may be accompanied by measurements using other modalities. Khandonker et al. [118] simultaneously acquired the abdominal fECG and Doppler US signals for improved identification of cardiac events, which allows the derivation of myocardial performance indices. While Kupka et al. [117] used time-frequency analysis of the Doppler US signal, Khandonker et al. [118] used multiresolution wavelet decomposition for automatic identification of cardiac valve motion. Furthermore, in [119], more sophisticated algorithms, e.g., empirical mode decomposition and hybrid support vector machines-hidden Markov models, for the automated estimation of fetal cardiac timing effects from CW Doppler US were used.

Besides standard Doppler, the clinical value of the Doppler US imaging in the context of fetal health assessment has been proven during labor. Hecher et al. [120] combined the Doppler US-based fHR monitoring with color flow imaging in a study on fetuses with intrauterine growth restriction. They concluded that the pulsatility index derived from the Doppler velocity waveform of the ductus venosus and a shunt between the umbilical vein and the inferior vena cava, together with short-term variations of fHR, are important markers for determining the optimal timing of delivery [120]. In the metaanalysis conducted by Alfirevic and Neilson [121], analysis of umbilical artery waveforms has also been identified as an important tool to prevent perinatal death and antenatal admissions. Doppler velocimetry during labor has been used to evaluate the pathophysiological mechanisms underlying fHR in compromised fetuses [122]. These analyses rely on an operator who positions the diagnostic US transducer and identifies the measurement site in the US images. Therefore, at this time, the full potential of Doppler US technology has not yet been brought to bear on continuous monitoring. However, with the development of operator-independent transducer arrays [80], this potential may be unlocked.

In a patent by Hoctor [123], a capacitive micromachined US transducer (CMUT) array is described, which allows insonifying a 3-D space to track the fetal heart when the fetus moves within the maternal abdomen. CMUT arrays are a relatively new type of US transducers, which have the potential to be cost-effective and can be integrated into miniaturized electronics [124]. Furthermore, they do not contain lead. The use of lead is a drawback of conventional piezoelectric transducers given environmental regulations [125]. It should be noted that the pitch (spacing) between individual transducer elements of multi-element transducer arrays used in clinical practice is relatively large. A large pitch, viz., a pitch larger than $\lambda / 2$, prevents using these arrays for effective beam steering without the creation of grating lobes [60]. New arrays suitable for beam steering need to be developed for fetal Doppler. Liu et al. [126] believe that for the automatic selection of the correct SV, artificial intelligence may be a key enabling technology for identification of the heart location.

\section{B. Improving Accessibility and Reducing Costs}

The nonstress test CTG is a sensitive tool to detect fetuses in immediate danger of deterioration and compromise [127], but performing regular monitoring sessions in the clinic is time-consuming and cost-inefficient [128] and, therefore, tele-monitoring of fHR, not only limited to the Doppler US technology, is gaining more and more interest [127], [129], [130]. In the study performed by Boatin et al. [130], a Doppler US transducer is positioned by trained personnel before a wireless monitoring session is initiated, whereas in [127], mothers are trained to perform the whole measurement session, including transducer positioning, on their own. In a questionnaire conducted by Brown et al. [131], professionals were asked for their opinion on long-term continuous fetal monitoring, concluding that the majority of clinicians have a positive opinion but have concerns that such systems may increase maternal anxiety. It should be noted that clinicians are concerned about the increased availability of handheld US Doppler devices as they, even though safety limits are met, are accompanied by the danger of wrong reassurance [132]. A key requirement of fHR monitoring at home is that it is foolproof [130]. Operator-independent systems as described in [80] may be a step into this direction.

Another important direction of technological development of Doppler US systems is to make them accessible and affordable in low-income and middle-income countries. Approximately $98 \%$ of all annual, global stillbirths occur in these countries, and fHR monitoring and labor surveillance is regarded as one of the key interventions for prevention [133]. In 2016, as alternative to the Pinard horn, Byaruhanga et al. [21] evaluated the use of a low-cost handheld fetal Doppler device powered by a hand crank generator allowing fHR recordings sessions of several minutes. In another recent study, a novel low-cost Doppler US-based fHR monitor device has been successfully implemented and evaluated in resource-limited hospitals [134].

\section{CONCLUSION}

In this article, the Doppler US technology for fHR monitoring is thoroughly described. Over the years, different 
transducer designs, signal processing techniques, and fHR extraction methods have been developed for more accurate and more robust monitoring of the fHR. Until this date, Doppler US is the most used technology in clinical practice and, with further technological developments, it will remain an important tool for the assessment of fetal well-being.

\section{ACKNOWLEDGMENT}

The research reported in this article was performed within the framework of the Eindhoven MedTech Innovation Center, Eindhoven, The Netherlands.

\section{References}

[1] E. H. Hon and O. W. Hess, "The clinical value of fetal electrocardiography," Amer. J. Obstetrics Gynecol., vol. 79, pp. 1012-1023, May 1960.

[2] H. Alvarez and R. Caldeyro-Barcia, "The normal and abnormal contractile waves of the uterus during labour," Int. Monthly Rev. Obstetrics Gynecol., vol. 138, no. 2, pp. 190-212, 1954.

[3] K. Hammacher, "New method for the selective registration of the fetal heart beat," Geburtshilfe Frauenheilkunde, vol. 22, pp. 1542-1543, Dec. 1962.

[4] J. B. Hoppe, "Measure-Great expectations: Celebrating 30 years of HP fetal monitors," Measure, pp. 4-6, Jul./Aug. 1998.

[5] D. Ayres-de-Campos, "Electronic fetal monitoring or cardiotocography, 50 years later: What's in a name?" Amer. J. Obstetrics Gynecol., vol. 218, no. 6, pp. 545-546, Jun. 2018.

[6] J. Adam, "The future of fetal monitoring," Rev. Obstetrics Gynecol., vol. 5, nos. 3-4, p. e132, 2012.

[7] D. Ayres-de-Campos, C. Y. Spong, and E. Chandraharan, "FIGO consensus guidelines on intrapartum fetal monitoring: Cardiotocography," Int. J. Gynecol. Obstetrics, vol. 131, no. 1, pp. 13-24, 2015.

[8] R. Victory, D. Penava, O. da Silva, R. Natale, and B. Richardson, "Umbilical cord $\mathrm{pH}$ and base excess values in relation to adverse outcome events for infants delivering at term," Amer. J. Obstetrics Gynecol., vol. 191, no. 6, pp. 2021-2028, 2004.

[9] C. V. Ananth, S. P. Chauhan, H.-Y. Chen, M. E. D'Alton, and A. M. Vintzileos, "Electronic fetal monitoring in the United States: Temporal trends and adverse perinatal outcomes," Obstetrics Gynecol., vol. 121, no. 5, pp. 927-933, 2013.

[10] Z. Alfirevic, D. Devane, and G. M. L. Gyte, "Continuous cardiotocography (CTG) as a form of electronic fetal monitoring (EFM) for fetal assessment during labour," Cochrane Database Syst. Rev., vol. 3, no. 3, 2006, Art. no. CD006066.

[11] E. L. Barber et al., "Indications contributing to the increasing cesarean delivery rate," Obstetrics Gynecol., vol. 118, no. 1, pp. 29-38, 2011.

[12] S. Schiermeier, G. Westhof, A. Leven, H. Hatzmann, and J. Reinhard, "Intra- and interobserver variability of intrapartum cardiotocography: A multicenter study comparing the figo classification with computer analysis software," Gynecol. Obstetrics Invest., vol. 72, no. 3, pp. 169-173, 2011.

[13] P. A. Warrick, E. F. Hamilton, R. E. Kearney, and D. Precup, "A machine learning approach to the detection of fetal hypoxia during labor and delivery," AI Mag., vol. 33, no. 2, pp. 1865-1870, 2012.

[14] V. Chudáček et al., "Assessment of features for automatic CTG analysis based on expert annotation," in Proc. Annu. Int. Conf. IEEE Eng. Med. Biol. Soc., Aug./Sep. 2011, pp. 6051-6054.

[15] G. S. Dawes, M. Lobb, M. Moulden, C. W. G. Redman, and T. Wheeler, "Antenatal cardiotocogram quality and interpretation using computers," BJOG, Int. J. Obstetrics Gynaecol., vol. 99, no. 10, pp. 791-797, Oct. 1992.

[16] M. Doret, J. Spilka, V. Chudáček, P. Gonçalves, and P. Abry, "Fractal analysis and Hurst parameter for intrapartum fetal heart rate variability analysis: A versatile alternative to frequency bands and LF/HF ratio," PLoS ONE, vol. 10, no. 8, 2015, Art. no. e0136661.

[17] J. O. E. H. van Laar, C. H. L. Peters, S. Houterman, P. F. F. Wijn, A. Kwee, and S. G. Oei, "Normalized spectral power of fetal heart rate variability is associated with fetal scalp blood pH," Early Hum. Develop., vol. 87, no. 4, pp. 259-263, Apr. 2011.

[18] G. J. J. Warmerdam et al., "Using uterine activity to improve fetal heart rate variability analysis for detection of asphyxia during labor," Physiol. Meas., vol. 37, no. 3, pp. 387-400, 2016.
[19] M. C. Leiva et al., "Fetal cardiac development and hemodynamics in the first trimester," Ultrasound Obstetrics Gynecol., vol. 14, no. 3 , pp. 169-174, 1999.

[20] R. Martis, O. Emilia, D. S. Nurdiati, and J. Brown, "Intermittent auscultation (IA) of fetal heart rate in labour for fetal well-being," Cochrane Database Syst. Rev., no. 2, pp. 1-68, 2017, Art. no. CD008680. doi: 10.1002/14651858.CD008680.pub2.

[21] R. Byaruhanga, D. G. Bassani, A. Jagau, P. Muwanguzi, A. L. Montgomery, and J. E. Lawn, "Use of wind-up fetal Doppler versus Pinard for fetal heart rate intermittent monitoring in labour: A randomised clinical trial," BMJ Open, vol. 5, no. 1, 2015, Art. no. e006867.

[22] P. Bakker, G. J. Colenbrander, A. A. Verstraeten, and H. P. Van Geijn, "The quality of intrapartum fetal heart rate monitoring," Eur. J. Obstetrics Gynecol. Reproductive Biol., vol. 116, no. 1, pp. 22-27, 2004.

[23] V. Maiques, A. García-Tejedor, A. Perales, and C. Navarro, "Intrapartum fetal invasive procedures and perinatal transmission of HIV," Eur. J. Obstetrics Gynecol. Reproductive Biol., vol. 87, no. 1, pp. 63-67, 1999.

[24] R. Vullings, Non-Invasive Fetal Electrocardiogram: Analysis and Interpretation. Eindhoven, The Netherlands: Technische Universiteit Eindhoven, 2010.

[25] R. Sameni and G. D. Clifford, "A review of fetal ECG signal processing; issues and promising directions," Open Pacing, Electrophysiol. Therapy J., vol. 3, p. 4, Jan. 2010.

[26] T. F. Oostendorp, A. Van Oosterom, and H. W. Jongsma, "Electrical properties of tissues involved in the conduction of foetal ECG," Med. Biol. Eng. Comput., vol. 27, no. 3, pp. 322-324, 1989.

[27] P. C. Adithya, R. Sankar, W. A. Moreno, and S. Hart, "Trends in fetal monitoring through phonocardiography: Challenges and future directions," Biomed. Signal Process. Control, vol. 33, pp. 289-305, Mar. 2017

[28] K. B. Gan, E. Zahedi, and M. A. M. Ali, "Transabdominal fetal heart rate detection using NIR photopleythysmography: Instrumentation and clinical results," IEEE Trans. Biomed. Eng., vol. 56, no. 8, pp. 2075-2082, Aug. 2009.

[29] I. Kiefer-Schmidt et al., "Fetal magnetocardiography (fMCG): Moving forward in the establishment of clinical reference data by advanced biomagnetic instrumentation and analysis," J. Perinatal Med., vol. 40, no. 3, pp. 277-286, 2012.

[30] C. H. L. Peters et al., "Beat-to-beat detection of fetal heart rate: Doppler ultrasound cardiotocography compared to direct ECG cardiotocography in time and frequency domain," Physiol. Meas., vol. 25, no. 2, pp. 585-593, Apr. 2004

[31] J. Reinhard et al., "Intrapartum signal quality with external fetal heart rate monitoring: A two way trial of external Doppler CTG ultrasound and the abdominal fetal electrocardiogram," Arch. Gynecol. Obstetrics, vol. 286, no. 5, pp. 1103-1107, Nov. 2012

[32] I. Voicu, J. M. Girault, C. Roussel, A. Decock, and D. Kouame, "Robust estimation of fetal heart rate from US Doppler signals," Phys. Procedia, vol. 3, no. 1, pp. 691-699, 2010.

[33] J. Wróbel, D. Roj, J. Jeżewski, and K. Horoba, "The influence of signal loss episodes on fetal heart rate variability measures," J. Med. Inform. Technol., vol. 23, pp. 35-42, 2014.

[34] D. Ayres-de Campos and J. Bernardes, "Twenty-five years after the FIGO guidelines for the use of fetal monitoring: Time for a simplified approach?" Int. J. Gynecol. Obstetrics, vol. 110, no. 1, pp. 1-6, 2010.

[35] F. Marzbanrad, L. Stroux, and G. D. Clifford, "Cardiotocography and beyond: A review of one-dimensional Doppler ultrasound application in fetal monitoring," Physiol. Meas., vol. 39, no. 8, 2018, Art. no. 08TR01.

[36] R. M. Grivell, Z. Alfirevic, G. M. L. Gyte, and D. Devane, "Antenatal cardiotocography for fetal assessment," Cochrane Database Syst. Rev., vol. 9, no. 1, pp. 1-57, 2015, Art. no. CD007863. doi: 10.1002/14651858.CD007863.pub2.

[37] K. T. M. Schneider, "S1-guideline on the use of CTG during pregnancy and labor," Geburtshilfe Frauenheilkunde, vol. 74, no. 8, pp. 721-732, Aug. 2014.

[38] D. Ayres-De-Campos and Z. Nogueira-Reis, "Technical characteristics of current cardiotocographic monitors," Best Practice Res. Clin. Obstetrics Gynaecol., vol. 30, pp. 22-32, Jan. 2016.

[39] G. Cito, S. Luisi, A. Mezzesimi, C. Cavicchioli, G. Calonaci, and F. Petraglia, "Maternal position during non-stress test and fetal heart rate patterns," Acta obstetricia Gynecol. Scandinavica, vol. 84, no. 4, pp. 335-338, 2005. 
[40] E. R. Cluett, E. Burns, and A. Cuthbert, "Immersion in water during labour and birth," Cochrane Database Syst. Rev., vol. 5, no. 2, pp. 1-55, 2009, Art. no. CD000111. doi: 10.1002/14651858.CD000111.pub3.

[41] RCM Midwifery Blue Top Guidance, "Midwifery care in labour guidance for all women in all settings," RCM Midwifery Blue Top Guid., vol. 11, no. 1, pp. 1-28, 2018.

[42] E. N. Marieb and K. Hoehn, Human Anatomy \& PhysiologyPregnancy and Huaman Development. London, U.K.: Pearson, 2007.

[43] World Health Organization, Global Status Report on Noncommunicable Diseases. Geneva, Switzerland: WHO, 2014.

[44] M. Morgenstern, J. D. Sargent, and R. Hanewinkel, "Relation between socioeconomic status and body mass index: Evidence of an indirect path via television use," Archives Pediatrics Adolescent Med., vol. 163, no. 8, pp. 731-738, 2009.

[45] J. C. P. Ferreira et al., "The evolution of fetal presentation during pregnancy: A retrospective, descriptive cross-sectional study," Acta obstetricia Gynecol. Scandinavica, vol. 94, no. 6, pp. 660-663, 2015.

[46] J. I. P. de Vries, G. H. A. Visser, and H. F. R. Prechtl, "The emergence of fetal behaviour. I. Qualitative aspects," Early Hum. Develop., vol. 7, no. 4, pp. 301-322, Dec. 1982.

[47] M. D. Velazquez and W. F. Rayburn, "Antenatal evaluation of the fetus using fetal movement monitoring," Clin. Obstetrics Gynecol., vol. 45, no. 4, pp. 993-1004, 2002.

[48] L. D. Longo and J. B. Hicks, "On the contractions of the uterus throughout pregnancy: Their physiological effects and their value in the diagnosis of pregnancy," Trans. Obstetrics Soc. London, vol. 13, pp. 216-237, Oct. 1872.

[49] Z. S. Kellow and V. A. Feldstein, "Ultrasound of the placenta and umbilical cord: A review," Ultrasound Quart., vol. 27, no. 3, pp. 187-197, 2011.

[50] D. N. White, G. R. Curry, and R. J. Stevenson, "The acoustic characteristics of the skull," Ultrasound Med. Biol., vol. 4, no. 3, pp. 225-239, 1978.

[51] P. Gentili, A. Trasimeni, and C. Giorlandino, "Fetal ossification centers as predictors of gestational age in normal and abnormal pregnancies," J. Ultrasound Med., vol. 3, no. 5, pp. 193-197, 1984.

[52] J. W. Wladimiroff, P. A. Stewart, and R. P. L. Vosters, "Fetal cardiac structure and function as studied by ultrasound," Clin. Cardiol., vol. 7 , no. 5, pp. 239-253, 1984.

[53] S. Luewan, Y. Yanase, F. Tongprasert, K. Srisupundit, and T. Tongsong, "Fetal cardiac dimensions at 14-40 weeks' gestation obtained using cardio-STIC-M," Ultrasound Obstetrics Gynecol. vol. 37, no. 4, pp. 22-416, 2011.

[54] B. Tutschek, T. Zimmermann, T. Buck, and H. G. Bender, "Fetal tissue Doppler echocardiography: Detection rates of cardiac structures and quantitative assessment of the fetal heart," Ultrasound Obstetrics Gynecol., vol. 21, no. 1, pp. 26-32, 2003.

[55] N. N. Elmstedt et al., "Reference values for fetal tissue velocity imaging and a new approach to evaluate fetal myocardial function," Cardiovascular Ultrasound, vol. 11, no. 1, p. 29, 2013.

[56] K. L. Reed, E. J. Meijboom, D. J. Sahn, S. A. Scagnelli, L. M. Valdes-Cruz, and L. Shenker, "Cardiac Doppler flow velocities in human fetuses," Circulation, vol. 73, no. 1, pp. 41-46, 1986.

[57] S. P. von Steinburg et al., "What is the 'normal' fetal heart rate?" PeerJ, vol. 1, p. e82, 2013.

[58] D. Ayres-De-Campos, "Introduction: Why is intrapartum foetal monitoring necessary-impact on outcomes and interventions," Best Practice Res. Clin. Obstetrics Gynaecol., vol. 30, pp. 3-8, Jan. 2016.

[59] J. E. Carreiro, An Osteopathic Approach to Children, C. Livingstone, Ed., 2nd ed. Amsterdam, The Netherlands: Elsevier, 2009, pp. 73-83.

[60] R. S. C. Cobbold, Foundations of Biomedical Ultrasound. Oxford, U.K.: Oxford Univ. Press, 2007.

[61] P. Hamelmann et al., "Improved ultrasound transducer positioning by fetal heart location estimation during Doppler based heart rate measurements," Physiol. Meas., vol. 38, no. 10, pp. 1821-1836, Sep. 2017

[62] P. Hamelmann, R. Vullings, M. Mischi, A. F. Kolen, L. Schmitt, and J. W. M. Bergmans, "An extended Kalman filter for fetal heart location estimation during Doppler-based heart rate monitoring," IEEE Trans. Instrum. Meas., vol. 68, no. 9, pp. 3221-3231, Sep. 2019.

[63] I. Voicu, S. Ménigot, D. Kouamé, and J. M. Girault, "New estimators and guidelines for better use of fetal heart rate estimators with Doppler ultrasound devices," Comput. Math. Methods Med., vol. 2014, pp. 1-10, Jan. 2014.
[64] B. Karlsson et al., "The DopFet system: A new ultrasonic Doppler system for monitoring and characterization of fetal movement," Ultrasound Med. Biol., vol. 26, no. 7, pp. 1117-1124, 2000.

[65] K. Foulquiere, B. Karlsson, G. Vilbergsson, and M. Berson, "Using modified fetal monitor and signal processing to detect fetal breathing movement," in Proc. IEEE Ultrason. Symp., vol. 2, Oct. 2000, pp. 1391-1394.

[66] B. Karlsson, D. Pourcelot, T. Helgason, L. Pourcelot, and M. Berson, "Distance of foetal movement measured using the analytical signal derived from non-directional Doppler sound," Med. Eng. Phys., vol. 20, no. 5, pp. 325-331, 1998.

[67] D. Roj, T. Fuchs, M. Jezewski, A. Matonia, A. Gacek, and T. Przybyła, "The influence of window size of autocorrelation function on fetal heart rate variability measurement using the Doppler ultrasound signal," J. Med. Inform. Technol., vol. 12, Mar. 2008.

[68] J. Jezewski, J. Wrobel, and K. Horoba, "Comparison of Doppler ultrasound and direct electrocardiography acquisition techniques for quantification of fetal heart rate variability," IEEE Trans. Biomed. Eng., vol. 53, no. 5, pp. 855-864, May 2006.

[69] J. Jezewski, D. Roj, J. Wrobel, and K. Horoba, "A novel technique for fetal heart rate estimation from Doppler ultrasound signal," Biomed. Eng. OnLine, vol. 10, no. 1, p. 92, 2011.

[70] S. A. Shakespeare, "The information content of Doppler ultrasound signals from the fetal heart," Med. Biol. Eng. Comput., vol. 39, no. 6, pp. 619-626, Feb. 2001

[71] D. Paladini, "Sonography in obese and overweight pregnant women: Clinical, medicolegal and technical issues," Ultrasound Obstetrics Gynecol., vol. 33, no. 6, pp. 720-729, 2009.

[72] F. A. Duck, Physical Properties of Tissue: A Comprehensive Reference Book, vol. 18, no. 4. New York, NY, USA: Academic, 1991.

[73] J. A. Jensen and N. B. Svendsen, "Calculation of pressure fields from arbitrarily shaped, apodized, and excited ultrasound transducers," IEEE Trans. Ultrason., Ferroelectr., Freq. Control, vol. 39, no. 2, pp. 262-267, Mar. 1992.

[74] A. Ryspayeva, K. K. Andersen, L. Hoff, and K. Imenes, "Design of an ultrasound transducer for continuous fetal heartbeat monitoring," in Proc. IEEE Int. Ultrason. Symp. (IUS), 2017, pp. 1-4.

[75] A. Kribèche, F. Tranquart, D. Kouame, and L. Pourcelot, "The Actifetus system: A multidoppler sensor system for monitoring fetal movements," Ultrasound Med. Biol., vol. 33, no. 3, pp. 430-438, 2007.

[76] B. E. Treeby, J. Jaros, A. P. Rendell, and B. T. Cox, "Modeling nonlinear ultrasound propagation in heterogeneous media with power law absorption using a $k$-space pseudospectral method," J. Acoust. Soc. Amer., vol. 131, no. 6, pp. 4324-4336, Jun. 2012.

[77] P. Hamelmann et al., "Ultrasound transducer positioning aid for fetal heart rate monitoring," in Proc. 38th Annu. Int. Conf. IEEE Eng. Med. Biol. Soc. (EMBC), Orlando, FL, USA, Aug. 2016 , pp. 4105-4108.

[78] P. Hamelmann et al., "Flexible sensor matrix with dynamic channel weighting for improved estimation of the fetal heart rate by Doppler ultrasound," in Proc. IEEE Int. Ultrason. Symp. (IUS), Sep. 2017, pp. $1-4$.

[79] P. Hamelmann, R. Vullings, M. Misch, J. W. M. Bergsmans, A. F. Kolen, and J. O. E. H. van Laar, "Fetal heart rate measurements of twins using a single flexible transducer matrix," in Proc. IEEE Int. Ultrason. Symp. (IUS), Oct. 2018, pp. 1-4.

[80] P. Hamelmann, M. Mischi, A. F. Kolen, J. O. E. H. van Laar, R. Vullings, and J. Bergmans, "Fetal heart rate monitoring implemented by dynamic adaptation of transmission power of a flexible ultrasound transducer array," Sensors, vol. 19, no. 5, p. 1195, 2019.

[81] M. G. Ross, "How to differentiate maternal from fetal heart rate patterns on electronic fetal monitoring," $O B G$ Manag., vol. 30, no. 7, pp. 40-46, 2018.

[82] B. L. McFarlin, J. L. Engstrom, M. B. Sampson, F. Cattledge, M. Samspon, and F. Cattledge, "Concurrent validity of Leopold's maneuvers in determining fetal presentation and position," J. NurseMidwifery, vol. 30, no. 5, pp. 280-284, Sep. 1985.

[83] R. K. Freeman, T. J. Garite, M. P. Nageotte, and L. A. Miller, Fetal Heart Rate Monitoring, 4th ed. Philadelphia, PA, USA: Lippencott Williams and Wilkins, 2012.

[84] D. Groberman, T. Slonim, S. Hayun, and J. Rotem, "Fetal heart rate monitoring system," U.S.Patent 20160213349 A1, Jul. 28, 2016.

[85] G. Pison, C. Monden, and J. Smits, "Twinning rates in developed countries: Trends and explanations," Population Develop. Rev., vol. 41, no. 4, pp. 629-649, 2015. 
[86] A. Conde-Agudelo, J. M. Belizán, and G. Lindmark, "Maternal morbidity and mortality associated with multiple gestations," Obstetrics Gynecol., vol. 95, no. 6, pp. 899-904, Jun. 2000.

[87] M. S. Esplin and A. G. Eller, "10 tips for overcoming common challenges of intrapartum fetal monitoring," $O B G$ Manag., vol. 28, no. 5 , pp. 34-46, 2016.

[88] M. C. Ziskin, "Fundamental physics of ultrasound and its propagation in tissue," Radiographics, vol. 13, no. 3, pp. 705-709, May 1993

[89] G. T. Haar and S. Sm, "Ultrasonic imaging: Safety considerations," Interface Focus, vol. 1, pp. 686-697, May 2011.

[90] L. Kollmann, C. Ter Haar, G. Dolezal, L. Hennerici, M. Salvesen, and K. A. Valentin, "Ultrasound Output: Thermal (TI) and mechanical (MI) indices," Ultraschall Medizin, vol. 34, no. 5, pp. 422-434, 2013.

[91] S. Bly and M. C. Van den Hof, "Obstetric ultrasound biological effects and safety," J. Obstetrics Gynaecol. Canada, vol. 27, no. 6, pp. 572-580, Jun. 2005

[92] M. Wohlschlager and C. Franck, "Method of reducing ultrasound signal ambiguity during fetal monitoring," U.S. Patent 9107584 B2, Aug. 18, 2015.

[93] R. Jackson, "Fetal heart monitoring," U.S. Patent 20110172540 A1, Jul. 2011.

[94] J. A. Jensen, "An analysis of pulsed wave ultrasound systems for blood velocity estimation," in Acoustical Imaging, vol. 22. Boston, MA, USA: Springer, 1995, pp. 377-384.

[95] J. A. Jensen, Estimation of Blood Velocities Using Ultrasound: A Signal Processing Approach. Cambridge, U.K.: Cambridge Univ. Press, 1996.

[96] D. H. Evans and W. N. McDicken, Doppler Ultrasound: Physics, Instrumentation and Signal Processing. Hoboken, NJ, USA: Wiley, 2000.

[97] B. A. Coghlan and M. G. Taylor, "Directional Doppler techniques for detection of blood velocities," Ultrasound Med. Biol., vol. 2, no. 3 , pp. 181-188, 1976.

[98] N. Aydin, L. Fan, and D. H. Evans, "Quadrature-to-directional format conversion of Doppler signals using digital methods," Physiol. Meas., vol. 15 , no. 2, pp. 181-199, 1994.

[99] G. Bambi et al., "A novel ultrasound instrument for investigation of arterial mechanics," Ultrasonics, vol. 42, nos. 1-9, pp. 731-737, Apr. 2004.

[100] G. Urban, S. Ricci, F. Guidi, G. Bambi, P. Tortoli, and M. J. Paidas, "Real-time human fetal aorta velocity profile using global acquisition and signal processing (GASP)," Ultrasound Obstetrics Gynecol., vol. 27 , no. 6 , pp. 716-718, 2006

[101] F. H. Boehm, L. M. Fields, J. M. Hutchison, A. W. Bowen, and W. K. Vaughn, "The indirectly obtained fetal heart rate: Comparison of first-and second-generation electronic fetal monitors," Amer. J. Obstetrics Gynecol., vol. 155, no. 1, pp. 10-14, Jul. 1986.

[102] M. Y. Divon, F. P. Torres, S.-Y. Yeh, and R. H. Paul, "Autocorrelation techniques in fetal monitoring," Amer. J. Obstetrics Gynecol., vol. 151, no. 1, pp. 2-6, 185AD.

[103] J. Jezewski, T. Kupka, and K. Horoba, "Extraction of fetal heart-rate signal as the time event series from evenly sampled data acquired using Doppler ultrasound technique," IEEE Trans. Biomed. Eng., vol. 55, no. 2, pp. 805-810, Feb. 2008.

[104] M. Cesarelli, M. Romano, P. Bifulco, F. Fedele, and M. Bracale, "An algorithm for the recovery of fetal heart rate series from CTG data," Comput. Biol. Med., vol. 37, no. 5, pp. 663-669, 2007.

[105] J. Wrobel, J. Jezewski, D. Roj, T. Przybyla, R. Czabanski, and A. Matonia, "The influence of Doppler ultrasound signal processing techniques on fetal heart rate variability measurements," Int. J. Biol. Biomed. Eng., vol. 4, no. 4, pp. 79-87, 2010.

[106] G. Magenes, M. G. Signorini, and R. Sassi, "Automatic diagnosis of fetal heart rate: Comparison of different methodological approaches," in Proc. 23rd Annu. EMBS Int. Conf., İstanbul, Turkey, 2001, pp. 1604-1607.

[107] L. Stroux and G. D. Clifford, "The importance of biomedical signal quality classification for successful mHealth implementation," in Proc. Tech4Dev Int. Conf. UNESCO Chair Technol. Develop., Lausanne, Switzerland, Jun. 2014, pp. 1-9.

[108] C. E. Valderrama, F. Marzbanrad, L. Stroux, and G. D. Clifford, "Template-based quality assessment of the Doppler ultrasound signal for fetal monitoring," Frontiers Physiol., vol. 8, pp. 1-10, Jul. 2017.

[109] J. Morgenstern, U. Naumann, and T. Somville, "Cardiotocographic apparatus test," Geburtshilfe Frauenheilkd., vol. 46, no. 5, pp. 304-311, 1986.

[110] Y. Murata and C. B. Martin, "Systolic time intervals of the fetal cardiac cycle," Obstetrics Gynecol., vol. 44, no. 2, pp. 224-232, 1974.
[111] A. Mert, M. Sezdi, and A. Akan, "A test and simulation device for Doppler-based fetal heart rate monitoring," Turkish J. Elect. Eng. Comput. Sci., vol. 23, no. 4, pp. 1187-1194, 2015.

[112] C. S. Lee, M. Masek, C. P. Lam, and K. T. Tan, "Towards higher accuracy and better noise-tolerance for fetal heart rate monitoring using Doppler ultrasound," in Proc. IEEE Region 10 Annu. Int. Conf. (TENCON), Jan. 2009, pp. 1-6.

[113] C. E. Valderrama et al., "An open source autocorrelation-based method for fetal heart rate estimation from one-dimensional Doppler ultrasound," Physiol. Meas., vol. 40, no. 2, 2019, Art. no. 025005.

[114] E. Boni, A. C. H. Yu, S. Freear, J. A. Jensen, and P. Tortoli, "Ultrasound open platforms for next-generation imaging technique development," IEEE Trans. Ultrason., Ferroelectr., Freq. Control, vol. 65, no. 7, pp. 1078-1092, Jul. 2018.

[115] K. Maeda, "Invention of ultrasonic Doppler fetal actocardiograph and continuous recording of fetal movements," J. Obstetrics Gynaecol. Res., vol. 42, no. 1, pp. 5-10, 2016.

[116] T. Wheeler, K. Roberts, J. Peters, and A. Murrills, "Detection of fetal movement using Doppler ultrasound," Obstetrics Gynecol., vol. 70 no. 2, pp. 251-254, Aug. 1987.

[117] T. Kupka, J. Jezewski, A. Matonia, K. Horoba, and J. Wrobel, "Timing events in Doppler ultrasound signal of fetal heart activity," in Proc 26th Аnnu. Int. Conf. IEEE Eng. Med. Biol. Soc., vol. 3, Sep. 2004, pp. $337-340$.

[118] A. H. Khandoker et al., "Assessing the development of fetal myocardial function by a novel Doppler myocardial performance index," in Proc. Eng. Med. Biol. Soc., 2016, pp. 3753-3756.

[119] F. Marzbanrad et al., "Automated estimation of fetal cardiac timing events from Doppler ultrasound signal using hybrid models," IEEE J. Biomed. Heal. Informat., vol. 18, no. 4, pp. 1169-1177, Oct. 2014.

[120] K. Hecher et al., "Monitoring of fetuses with intrauterine growth restriction: A longitudinal study," Ultrasound Obstetrics Gynecol., vol. 18 , no. 6, pp. 564-570, 2001.

[121] Z. Alfirevic and J. P. Neilson, "Doppler ultrasonography in high-risk pregnancies: Systematic review with meta-analysis," Amer. J. Obstetrics Gynecol., vol. 172, no. 5, pp. 1379-1387, May 1995.

[122] D. Mihu et al., "Applications of Doppler ultrasound during labor," Med. Ultrasonogr., vol. 13, no. 2, pp. 141-149, 2011.

[123] R. T. Hoctor and K. E. Thomenius, "Method and apparatus for non-invasive ultrasonic fetal heart rate monitoring," U.S. Patent 20050251044 A1, May 4, 2004.

[124] O. Oralkan et al., "Capacitive micromachined ultrasonic transducers: Next-generation arrays for acoustic imaging?" IEEE Trans. Ultrason., Ferroelectr., Freq. Control, vol. 49, no. 11, pp. 1596-1610, Nov. 2002.

[125] T. R. Shrout and S. J. Zhang, "Lead-free piezoelectric ceramics: Alternatives for PZT?" J. Electroceram., vol. 19, no. 1, pp. 113-126, 2007.

[126] S. Liu et al., "Deep learning in medical ultrasound analysis: A review," Engineering, vol. 5, no. 2, pp. 261-275, 2019.

[127] R. Kerner, Y. Yogev, A. Belkin, A. Ben-Haroush, B. Zeevi, and M. Hod, "Maternal self-administered fetal heart rate monitoring and transmission from home in high-risk pregnancies," Int. J. Gynecol. Obstetrics, vol. 84, no. 1, pp. 33-39, 2004.

[128] S. Patel, H. Park, P. Bonato, L. Chan, and M. Rodgers, "A review of wearable sensors and systems with application in rehabilitation," J. Neuroeng. Rehabil., vol. 9, no. 1, p. 21, 2012.

[129] M. G. Signorini, A. Fanelli, and G. Magenes, "Monitoring fetal heart rate during pregnancy: Contributions from advanced signal processing and wearable technology," Comput. Math. Methods Med., vol. 2014, Jan. 2014, Art. no. 707581.

[130] A. A. Boatin et al., "Wireless fetal heart rate monitoring in inpatient full-term pregnant women: Testing functionality and acceptability," PLoS ONE, vol. 10, no. 1, 2015, Art. no. e0117043.

[131] R. Brown, E. D. Johnstone, and A. E. P. Heazell, "Professionals' views of fetal-monitoring support the development of devices to provide objective longer-term assessment of fetal wellbeing," J. Maternal-Fetal Neonatal Med., vol. 29, no. 10, pp. 1680-1686, 2016.

[132] A. Chakladar and H. Adams, "Dangers of listening to the fetal heart at home," BMJ, vol. 339, p. b4308, Nov. 2009.

[133] Lawn, "Ending preventable stillbirths: An executive summary for the Lancet's series," Lancet, pp. 1-8, 2016.

[134] B. A. Kamala et al., "Implementation of a novel continuous fetal Doppler (Moyo) improves quality of intrapartum fetal heart rate monitoring in a resource-limited tertiary hospital in Tanzania: An observational study," PLOS ONE, vol. 13, no. 10, 2018, Art. no. e0205698. 


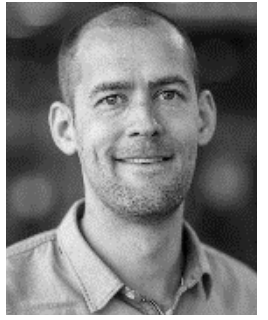

Paul Hamelmann was born in Freiburg im Breisgau, Germany, in 1988. He received the M.Sc. degree in biomedical engineering from the University of Twente, Enschede, The Netherlands, in 2013. He is currently pursuing the Ph.D. degree with the Signal Processing Group (BM/d Team), Eindhoven University of Technology (TU/e), Eindhoven, The Netherlands.

In collaboration with Philips Research, Eindhoven, and the Maxima Medical Center, Veldhoven, The Netherlands, he is working on the improvement of fetal heart rate monitoring using the Doppler ultrasound.

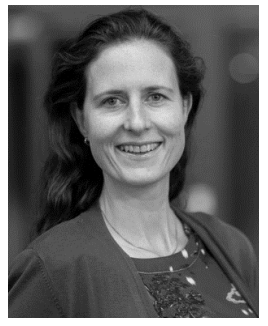

Judith O. E. H. van Laar received the master's degree in medicine from Radboud University, Nijmegen, The Netherlands, in 2004, and the Ph.D. degree from the Eindhoven University of Technology (TU/e), Eindhoven, The Netherlands, in 2012, with a focus on the fetal autonomic response during pregnancy and labor. She completed her specialization as a Gynecologist with the Máxima Medical Center, Eindhoven, in 2014.

She is currently a Gynecologist with the Máxima Medical Center and an Assistant Professor with TU/e.

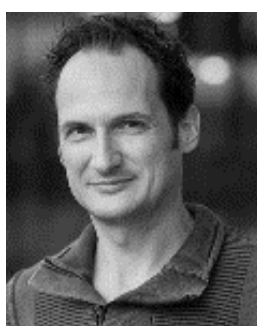

Rik Vullings received the M.Sc. degree (Hons.) in applied physics and the Ph.D. degree in electrical engineering, with a focus on the analysis and interpretation of the noninvasive fetal electrocardiogram, from the Eindhoven University of Technology (TU/e), Eindhoven, The Netherlands, in 2005 and 2010, respectively.

In 2009, he founded the spin-off company Nemo Healthcare, Veldhoven, The Netherlands, where he is currently the CSO. Since 2013, he has been an Assistant Professor with TU/e. His current research interests include model-based biomedical signal processing with applications in perinatology, cardiology, and somnology.

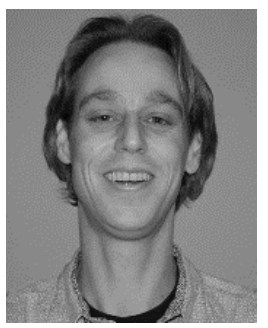

Alexander F. Kolen received the Ph.D. degree from the Institute of Cancer Research, University of London, London, U.K., in 2003.

From 2004 to 2005, he held a postdoctoral position at Maastricht University, Maastricht, The Netherlands, working on the analysis of cardiac mechanic using tissue Doppler ultrasound. In 2003, he joined Philips Research, Eindhoven, The Netherlands, leading several cardiac ultrasound-related projects. His research interests include the ultrasound diagnosis of liver tumours, followed by monitoring high-intensity focused ultrasound treatment bases on the ultrasound elastography.

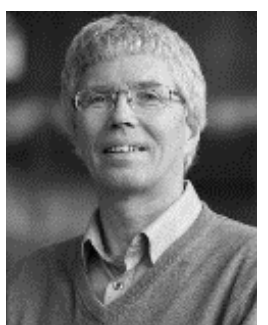

Jan W. M. Bergmans received the M.Sc. and Ph.D. degrees in electrical engineering from the Eindhoven University of Technology (TU/e), Eindhoven, The Netherlands, in 1981 and 1987, respectively.

From 1981 to 1982 , he was the Manager for communication projects at the Royal Netherlands Navy. From 1982 to 1999, he was with Philips Research Laboratories, Eindhoven. From 1988 to 1989 , he was an Exchange Researcher with the Digital Video Recording Group, Hitachi Central Research Laboratories, Tokyo, Japan. From 1991 to 1999, he coled a Research and Development Team, Philips Research, developing signal processing techniques and integrated circuits for data storage systems. In 1999, he was appointed as a Full Professor with TU/e and the Chair of the Signal Processing Systems Group. In 2000, he became a Scientific Advisor with the Philips Research Laboratories. Since 2006, he has been co-managing BrainBridge, Eindhoven, the strategic collaboration between TU/e, Philips Research, and Zhejiang University, Hangzhou, China.

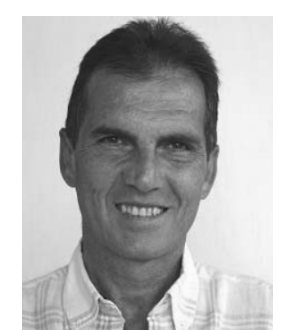

Piero Tortoli (M'91-SM'96) received the Laurea degree in electronics engineering from the University of Florence, Florence, Italy, in 1978.

Since then, he has been a Faculty Member with the Information Engineering Department, University of Florence, where he is currently a Full Professor of electronics, leading a group of over ten researchers in the Microelectronics Systems Design Laboratory. He has been an elected Member of the Academic senate with the University of Florence, since 2016. His research interests include the development of open ultrasound research systems and novel imaging/Doppler methods. On these topics, he has authored over 250 articles.

Prof. Tortoli was named an Honorary Member of the Polish Academy of Sciences in 2000. He has been serving on the IEEE International Ultrasonics Symposium Technical Program Committee since 1999 and is currently an Associate Editor of the IEEE TRANSACTIONS ON Ultrasonics, FERROELECTRICS, AND FREQUENCY CONTROL. He chaired the 22nd International Symposium on Acoustical Imaging in 1995, the 12th New England Doppler Conference in 2003, established the Artimino Conference on Medical Ultrasound in 2011, and organized it again in 2017.

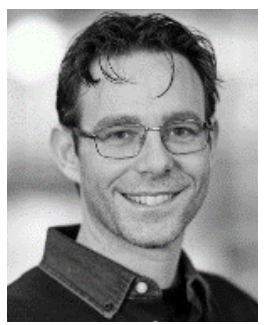

Massimo Mischi (M'02-SM'10) received the M.Sc. degree in electrical engineering from La Sapienza University, Rome, Italy, in 1999, and the Ph.D. degree from the Eindhoven University of Technology (TU/e), Eindhoven, The Netherlands, in 2004

In 2007, he became an Assistant Professor with the Electrical Engineering Department, TU/e. In 2011, he became an Associate Professor with TU/e and founded the Biomedical Diagnostics Research Lab, working on the model-based quantitative analysis of biomedical signals with applications ranging from electrophysiology to diagnostic imaging. He is currently a Full Professor with the Electrical Engineering Department, TU/e. He has coauthored over 250 peer-reviewed publications and several book chapters, and holds 11 patents.

Dr. Mischi is the Chairman of the IEEE EMBS Benelux Chapter. $\mathrm{He}$ is also a Board Member of the Imaging Section of the European Association of Urology and Secretary of the Dutch Society of Medical Ultrasound. He was then awarded with the STW VIDI Grant in 2009 and with the ERC Starting Grant in 2011 for his research on angiogenesis imaging. 